\title{
Laparoendoscopic Transgastric Resection of a Submucosal Mass at the Gastroesophageal Junction
}

\author{
Neil D. Ghushe • Parambir S. Dulai • Thadeus L. Trus
}

Received: 7 August 2012 / Accepted: 12 September 2012/Published online: 5 October 2012

(C) 2012 The Society for Surgery of the Alimentary Tract

\begin{abstract}
Introduction Traditional management of gastric submucosal lesions usually involves wedge resection. However, lesions close to the gastroesophageal junction are difficult to manage with wedge resection without compromising the lower esophageal sphincter. This video highlights an interesting combined laparoscopic and endoscopic technique for safe resection of a submucosal lesion adjacent to the gastroesophageal junction.

Methods A 66-year-old male was evaluated by gastroenterology for melena. Upper endoscopy with subsequent endoscopic ultrasound demonstrated a 2-cm submucosal lesion adjacent to the gastroesophageal junction. Biopsies were indeterminate, and the remainder of his workup was negative. A combined laparoendoscopic technique was utilized to safely resect the lesion while protecting the gastroesophageal junction. This was accomplished using three 5-mm trocars placed directly through the abdominal wall into the stomach using endoscopic guidance. All muscle layers were resected en bloc with the specimen, leaving the serosa intact.

Results The patient did well and was discharged home on postoperative day 1. Final pathology demonstrated a leiomyoma with negative margins.

Conclusion Submucosal lesions adjacent to the gastroesophageal junction can be safely and effectively managed using a laparoendoscopic approach. This technique provides improved visualization and facilitates an adequate resection compared to endoscopy or laparoscopy alone.
\end{abstract}

Electronic supplementary material The online version of this article (doi:10.1007/s11605-012-2038-8) contains supplementary material, which is available to authorized users.

P. S. Dulai · T. L. Trus

Dartmouth-Hitchcock Medical Center,

Lebanon, $\mathrm{NH}$, USA

N. D. Ghushe $(\bowtie)$

Division of General and Gastrointestinal Surgery,

Brigham and Women's Hospital,

Boston, MA, USA

e-mail: nghushe@partners.org
Keywords GIST $\cdot$ Laparoscopy $\cdot$ Therapeutic endoscopy • Submucosal mass $\cdot$ Laparoendoscopic

\section{References}

1. Walsh RM, Ponsky J, Brody F, Matthews BD, Heniford BT. J Gastrointest Surg. 2003 Mar-Apr;7(3):386-92. Combined endoscopic/laparoscopic intragastric resection of gastric stromal tumors.

2. Zhou PH, Yao LQ, Qin XY, Cai MY, Xu MD, Zhong YS, Chen WF, Zhang YQ, Qin WZ, Hu JW, Liu JZ. Surg Endosc. 2011 Sep;25 (9):2926-31. Epub 2011 Mar 18.Endoscopic full-thickness resection without laparoscopic assistance for gastric submucosal tumors originated from the muscularis propria. 